\title{
Comparative Analysis of Hysteroscopic Findings among infertile Women in Nigeria and in India: a Preliminary Investigation
}

Victor D Ajayi ${ }^{1}$, Abayomi B Ajayi ${ }^{1}$, B Ramesh ${ }^{2}$, Bamgboye M Afolabi ${ }^{3 *}$, Oluwafunmilola Biobaku' ${ }^{1}$, Ifeoluwa Oyetunji ${ }^{1}$

${ }^{1}$ Nordica Fertility and Endoscopy Centre, Nigeria

${ }^{2}$ Gynaecological Endoscopy and Infertility Centre, India

${ }^{3}$ Health, Environment and Development Foundation, Nigeria

Submission: July 12, 2017 ; Published: July 26, 2017

*Corresponding author: Bamgboye M Afolabi, Health, Environment and Development Foundation, 34 Montgomery Road, Yaba, Lagos, Nigeria, Email: bmafolabi@gmail.com

\begin{abstract}
Background: Hysteroscopy is considered the gold standard in assessing the uterine cavity for pathology. Uterine factors contribute significantly to etiology and treatment of infertility.

Objectives: To compare hysteroscopic findings among infertile Nigerian women and their Indian counterparts, determine if there are any differences and attempt to explain why the differences exist.

Methods: A retrospective study conducted at Nordica Fertility and Endoscopy Centre, Lagos, Nigeria and Dr. Ramesh Gynae, Endoscopy and Infertility Centre, Bangalore, India. The biodata and findings at hysteroscopy of 100 consecutive infertile Nigerian women who had hysteroscopy between January and December 2010 and 111 consecutive infertile women who also had hysteroscopy at about the same time at Bangalore, India were reviewed and compared. Analysis was done using SPSS version 17.0.

Results: There was a significant difference $(t=10.7, P$-value $=0.00001)$ in the mean $( \pm s d)$ age (years) of the Nigerian women at 39.3 (5.8) compared to 30.7 (5.9) among Indian women. Primary infertility (73.0\%) was a common finding among Indian women while secondary infertility $(66.0 \%)$ was more prevalent among Nigerian women who were over five times more likely to have this condition compared to Indian women $\left(x^{2}=32.2\right.$, P-value $=0.0001, \mathrm{OR}=5.2,95 \%$ CI: $\left.2.9,9.4\right)$. In all, 30 (27.0\%) and 78 (78.0\%) of Indian and Nigerian women respectively had abnormal hysteroscopic results. Nigerian women were about 10 times more likely to have an abnormal hysteroscopic outcome compared to Indian women $\left(\chi^{2}=54.7\right.$, P-value $=0.0001, \mathrm{OR}=9.6,95 \%$ CI: $\left.5.09,18.01\right)$. Intrauterine adhesion $(44.9 \%$ vs $13.3 \%)$ and sub-mucous fibroids $(21.8 \%$ vs $6.7 \%)$ were more pronounced among Nigerians while polyps (30.0\% vs $24.4 \%)$ and complete septum (6.7\% vs 5.1\%) were more common among Indians who had abnormal hysteroscopic findings. Indian women were 1.3 times more likely to present with polyps $\left(\chi^{2}=0.36, P\right.$-value $=0.55,0 R=1.33$, $95 \%$ CI: $0.52,3.40)$ and 1.32 times more likely to present with complete septum $\left(\chi^{2}=0.02\right.$, P-value $=0.75,0 R=1.32,95 \%$ CI: .23, 7.62$)$ than Nigerian
\end{abstract} women.

Conclusion: Sub-mucous fibroid and intra-uterine adhesion were more pronounced among Nigerians while polyps and complete septum were more common among Indian women.

Keywords: Hysteroscopy; Infertile women; Fibroid; Intra-uterine adhesion; Polyps; Complete septum

\section{Introduction}

In all societies of the world, infertility can be a distressing condition. The prevalence of infertility varies but is about $20 \%$ on the average. It is higher in certain parts of the world, Nigeria for instance where prevalence of up to $25 \%$ has been reported [1]. Infertility is the inability of a couple to achieve pregnancy after one year of regular, unprotected sexual intercourse. Primary infertility is infertility in a couple who have never conceived. Secondary infertility is failure to conceive following a previous pregnancy. Investigations need to be carried out to attempt to determine the cause of infertility where possible. Infertility can be due to male factor, female factor, combined factor or unexplained. The female factors include uterine cavity pathology which may be congenital or acquired such as uterine septum, intrauterine adhesions, uterine polyps, sub-mucous fibroids etc. Uterine factors may contribute up to $5 \%$ of causes of infertility [1]. A Nigerian study found uterine factor in up to $30 \%$ of the infertile women studied [2]. Identifying and treating some of these uterine factors where possible can positively impact on infertility. 
Hysteroscopy is considered the gold standard in assessing the uterine cavity. The objective of the study was to compare the hysteroscopic findings between infertile Nigerian and Indian women, determine if there are any differences and attempt to explain why.

\section{Methods and Materials}

The study was a retrospective one which was conducted at Nordica Fertility and Endoscopy Centre, Lagos, Nigeria and Dr. Ramesh Gynecologic Endoscopy and Infertility Centre, Bangalore, India. Both centres are located in modern capital cities with thriving economies and patronized by middle to high class members of their societies. The bio-data and findings

\section{Results}

Table 1: Summary of Key Findings.

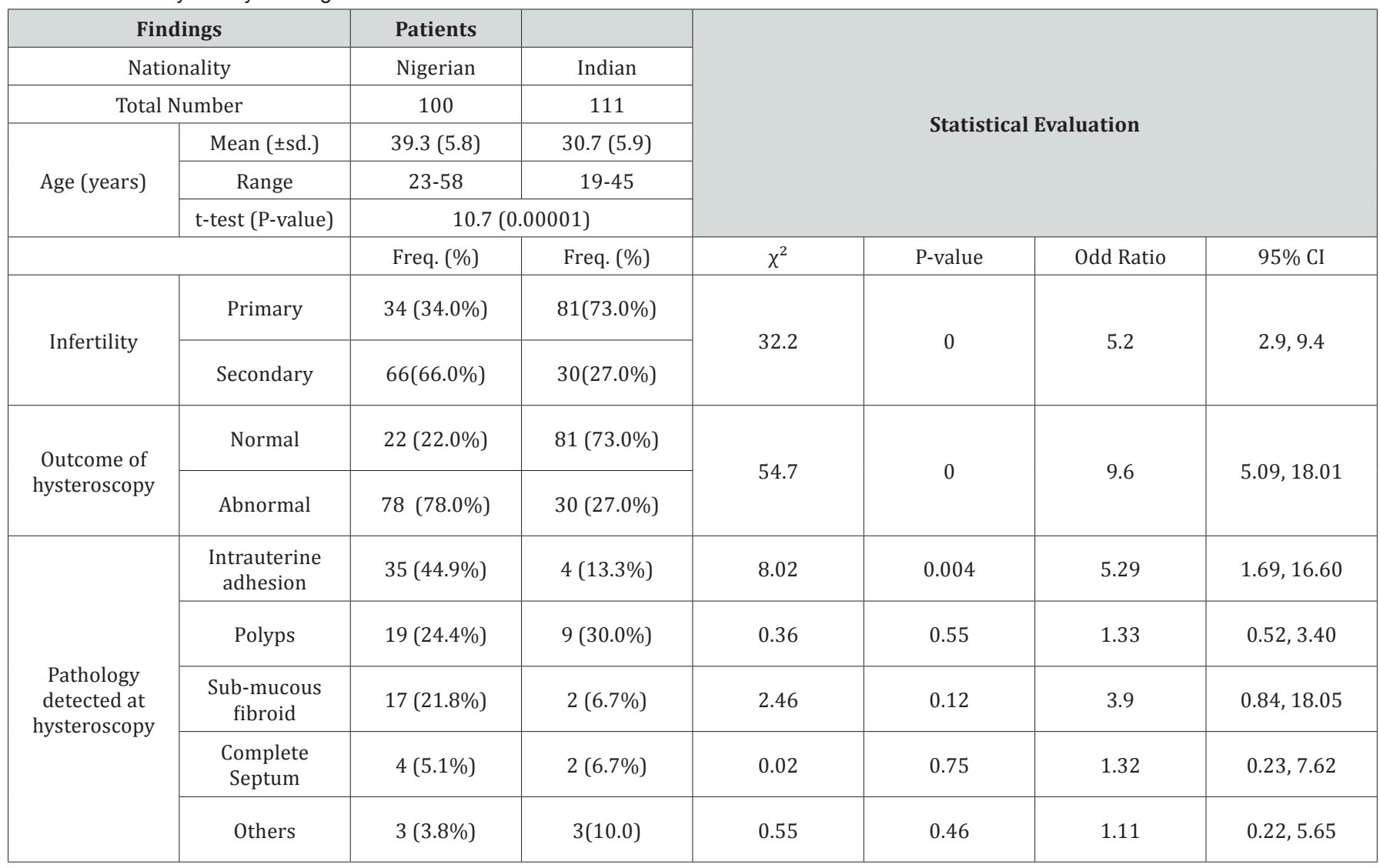

A total of 100 Nigerian and 111 Indian infertile women were studied. As shown in Table 1, Nigerian women who participated in the study were significantly older (39.3 \pm 5 .8 years; range 23-58 years) than Indian women (30.7 \pm 5.9 years; range $19-45$ years). Secondary infertility (Figure 1) was the commonest type of infertility among the Nigerian women accounting for $66 \%$ of cases of infertility while primary infertility was the commonest among the Indian women accounting for $73.0 \%$ of cases of infertility (Figure 2). Seventy eight (78.0\%) percent of Nigerian women had abnormal hysteroscopic findings compared to $27.0 \%$ of Indian women. The most common abnormality on hysteroscopy at hysteroscopy of 100 consecutive infertile Nigerian women who had hysteroscopy between January and December 2010 at Nordica Fertility Centre, Lagos, Nigeria and 111 consecutive infertile women who also had hysteroscopy between March and August 2010 at Dr Ramesh Gynae Endoscopy and Infertility Centre, Bangalore, India were reviewed and compared. The Nigerian data included data from the Asaba (South South Nigeria) and the Abuja (Northern Nigeria) branches of Nordica Fertility Centre, Lagos though all procedures were conducted in Lagos at the dedicated world class endoscopy center by the same set of experienced gynaecologists. Analysis was done using SPSS version 17.0. among Nigerian women was intrauterine adhesions (44.9\%) while among the Indians adhesions was seen in only $13.3 \%$ of pathologic cases with polyps being the commonest abnormality seen $30.0 \%$. Polyps accounted for $24.4 \%$ of abnormal findings among Nigerians.

Sub mucous uterine fibroids accounted for $21.8 \%$ of abnormal findings among Nigerian women compared to only $6.7 \%$ of Indian women. Complete uterine septum was seen in $5.1 \%$ and $6.7 \%$ of Nigerian and Indian women respectively Figure 3 . 

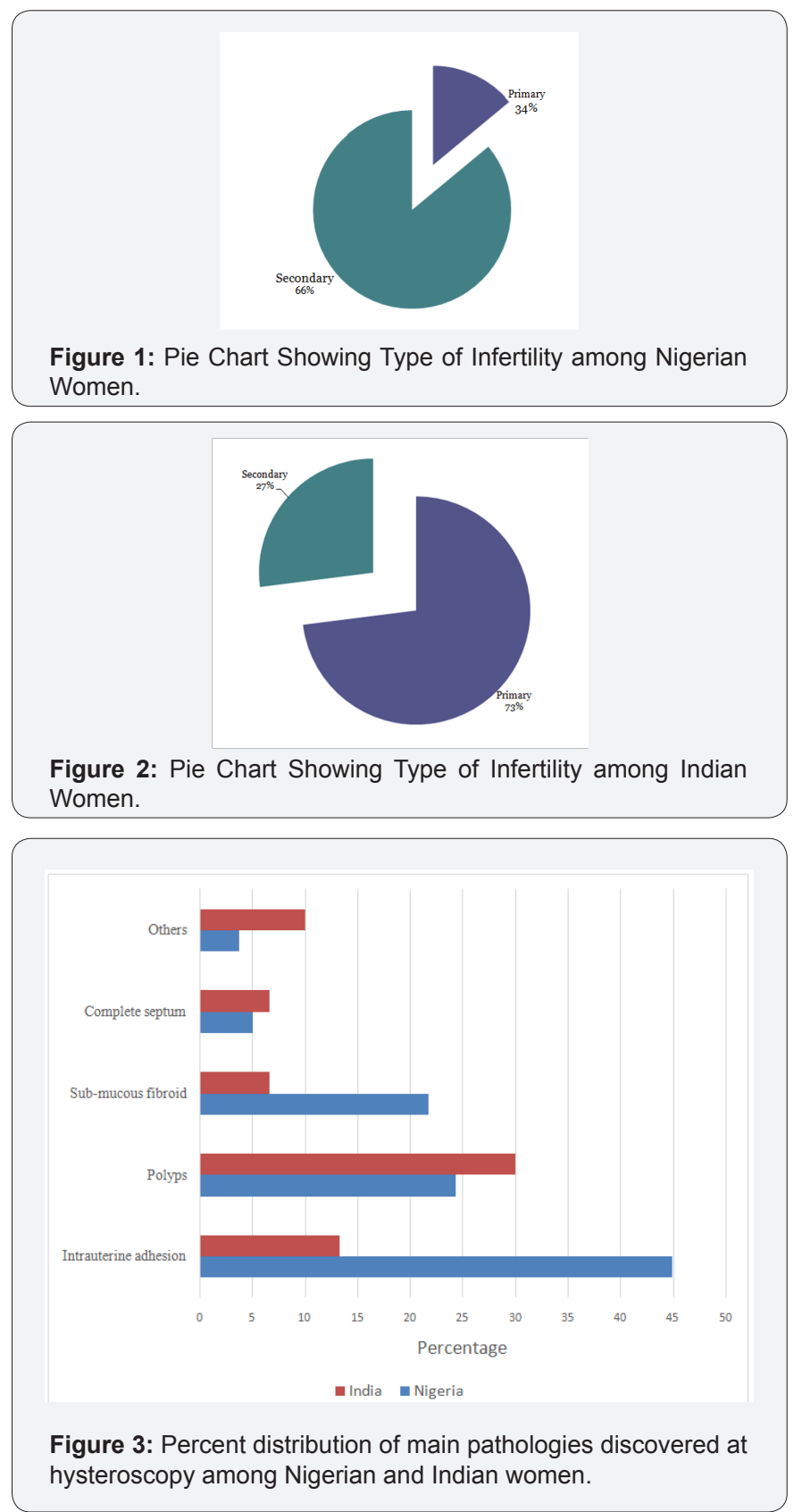

\section{Discussion}

Nigerian women were significantly much older than their Indian counterparts $(\mathrm{t}=10.7$, P-value $=0.00001)$. This could be because infertile Indians women presented early for evaluation as well as better awareness among these women. Nigerians traditionally seek alternative means of treatment before presenting to medical facilities and hysteroscopy is neither readily available nor widespread in Nigeria.

Nigerian women were 5 times more likely to have secondary infertility compared to the Indians who were more likely to have primary infertility $\left(\chi^{2}=32.2\right.$, P-value $=0.0001, \mathrm{OR}=5.2,95 \%$ CI: 2.9, 9.4). Sule et al. [1], Esima et al. [2] and Orhue \& Aziken [3] separately found secondary infertility to be commoner than primary infertility in their Nigerian studies $(77.5 \%$., $62 \%$ and $85.7 \%$ respectively). We found secondary infertility accounting for $66 \%$ of infertility in this study. Secondary infertility has been the major type of infertility in sub Saharan Africa and this has been attributed to high prevalence of sexually transmitted infections, inadequate treatment of such infections, unsafe abortion and its complications and puerperal sepsis [4].

Bongaarts et al. [5] described 9 major proximate determinants of fertility among which were marriage or union patterns, contraception, induced abortion and frequency of intercourse. There may be significant differences in these factors between the two societies reported in this study.

Fertility levels in sub-Saharan Africa are among the highest in the world. The Total Fertility rate (2016 estimates) for Nigeria was 5.13 compared to 2.45 for India with the financial times report by James Lamont in 2011 indicating that close to $10 \%$ of Indian households opting to have only one child. A Nigerian study by Adiri et al. reported a total fertility rate (TFR) of 7.97 in Northern Nigeria. Among both men and women, desired family size was high, with $37 \%$ of women citing 5-9 children as ideal and $32 \%$ citing $10-14$ children as ideal. Fewer than $20 \%$ of women wanted less than five children [6].

Uterine cavity pathology was significantly more likely among the Nigerian women $(78 \%)$ than the Indian women (27\%). The Nigerians were close to 10 times more likely to have abnormal uterine pathology at hysteroscopy $\left(\chi^{2}=54.7\right.$, $\mathrm{P}$-value $=0.0001, \mathrm{OR}=9.6,95 \% \mathrm{CI}: 5.09,18.01)$. Intrauterine adhesion was commonest among Nigerians who were 5 times more likely $\left(\chi^{2}=8.02, \mathrm{P}\right.$-value $=0.004, \mathrm{OR}=5.2,95 \% \mathrm{CI}$ : $1.69,16.60)$ to have intrauterine adhesions than the Indians, where it accounted for up to $45 \%$ of the pathology identified. Only $13.3 \%$ of the Indians with pathology had intrauterine adhesions. It was not the commonest finding among Indians. The high incidence of intrauterine adhesions among Nigerians could result in increased risk of miscarriages and therefore it is not surprising that secondary infertility was the commoner type of infertility among them. Complications following poorly supervised deliveries and unsafe abortions could be responsible for high incidence of intrauterine adhesions among Nigerians setting up a vicious cycle. It is interesting to observe that the number of Indian women with primary infertility was very similar to the number with normal hysteroscopic findings and also for secondary infertility and abnormal uterine findings at hysteroscopy. Could previous pregnancy be a strong factor in uterine anomalies? And could this be the reason why Nigerian women with a high prevalence of secondary infertility show a higher incidence of uterine abnormality especially those ones complicating or associated with pregnancy and its management such as intrauterine adhesions as found in this study?

Strict social restrictions among Indians may lead to less exposure to sex, unwanted pregnancy and its sequelae such as induced abortion. In addition, Abortion laws are more liberal in 
India compared to Nigeria where the law is restrictive. Abortion laws have been liberal in India since 1971 [7,8]. Societies with restrictive abortions laws have been shown to have higher incidence of unsafe abortion as this pushes abortion to dark alleys by untrained hands with increased risks of complications like intrauterine adhesions. One of the risk factors of Intrauterine adhesions is Dilatation and Curettage and the number of times this is done as reported by Ajayi et al. [9].

Home deliveries or poorly supervised deliveries are not uncommon in Nigeria and this could lead to complications such as puerperal sepsis which could contribute to a higher incidence of intrauterine adhesions [7]. Also, alternative treatment, harmful socio-cultural beliefs and practices such as insertion of concoctions and foreign bodies in the vagina to treat uterine pathology are common in certain parts of Nigeria.

Fibroids expectedly were more common among the Nigerians who are of black origin. Though not statistically significant, Nigerians were 4 times more likely to have sub-mucous fibroids at hysteroscopy [P-value=0.12]. Fibroids are known to be commoner in blacks. Advanced age at presentation by the Nigerian women could also be a factor in the higher incidence of fibroids seen in them. Fibroids are not only more common among Nigerians but they are usually bigger, multiple, more difficult to operate, typically recurrent and with a proliferation of nonexperts performing such open myomectomies complications may result which could lead to intrauterine adhesions. Open myomectomies and frequency of these operations have been reported as a risk factor for Intrauterine adhesion (IUA) in Nigerian women [9].

Endometrial polyps were commoner among the Indian women compared to the Nigerian women and were the commonest of the pathologies among the Indians. Hypertension and obesity though not conclusively proven, have been linked to uterine polyps. Even though data on the body mass index and blood pressure of the patients studied was not included in this study, India has been reported in a study published in the Lancet, to be the third most obese country in the world after the United States and China as its economic status increases and as more processed foods are consumed [10].

Complete septum had similar incidence in both groups of women though slightly higher among Indians. The incidence in both groups was similar to a study by Chan and colleagues showing that canalization defects, namely sub-septate or septate uteri had a prevalence of $2.3 \%$ in the unselected population [11]. Canalization defects are no more prevalent in women with infertility in general compared with the unselected population, though these defects were significantly more common in women with miscarriage especially if this is combined with a history of infertility [11].

\section{Conclusion}

It is concluded from this study that there are significant differences in hysteroscopic findings between infertile Nigerian and Indian women. These may be explained by peculiar sociocultural and reproductive experiences each group of infertile women are exposed to. This may also account for differing prevalence in type of infertility in each group. Taking measures such as enlightening Nigerian women on need for early presentation, avoidance of harmful socio-cultural beliefs and practices and availing themselves of expert care in gynaecological issues, liberalizing abortion laws and training and retraining of medical practitioners on general best practice among others may mitigate acquired uterine factors and thus help in the prevention and treatment of infertility as well as improve pregnancy outcomes. Further larger studies with more variables comparing different societies are encouraged.

\section{Limitations}

Some data that could have increased the strength of the study like more socio demographics and body mass index were not collected especially in the India arm of the study. A larger prospective study will address some of the shortfalls of this study.

\section{References}

1. Sule JO, Engbali P, Eruom L (2008) Prevalence of Infertility in Women in a Southwestern Nigerian Community. African Journal of Biomedical Research 11(2008): 225-227.

2. Esima OA, Orji EO, Lasisi AR (2002) Male Contribution to Infertility in Ile-Ife, Nigeria. Nigerian Niger J Med 11(2): 70-72.

3. Orhue A, Aziken M (2008) Experience with a Comprehensive University Hospital Based Infertility Program in Nigeria. Int J Gynaecol Obstet 101(1): 11-15.

4. Nwajiaku LA, Mbachu II, Ikeako L (2012) Prevalence, Pattern and Major Causes of Male Infertility in Nnewi South East Nigeria: A Five Year Review. Afrimedic Journal 3(2).

5. Jolly CL, Gribble JN (1984) The Proximate Determinants of Fertility In Demographic Change in Sub Saharan Africa. Population and Development Review 10(3): 511-537.

6. Adiri F, Ibrahim HI, Ajayi V, Sulayman HU, Yafeh AM, et al. (2010) Fertility Behaviour of Men and Women in Three Communities in Kaduna State, Nigeria. African Journal of Reproductive Health Sept 14(3): 97.

7. Oye-Adeniran B, Long CM, Adewole IF (2014) Advocacy for Reform of the Abortion Law in Nigeria. Reproductive Health Matters 12(24 Suppl): 209-217.

8. Siddhivinayak SH (2004) Abortion Law, Policy and Services in India: A Critical Review. Reprod Health Matters 12(24 Suppl): 114-121.

9. Ajayi AB, Afolabi BM, Ajayi V, Biobaku O, Oyetunji I, et al. (2017) Risk Factors for Intrauterine Adhesions in a Black African populationNigerians. Gynaecol Obstet (Sunnyvale) 7: 436.

10. Ng M, Fleming T, Robinson M et al. (2013) Global, regional, and national prevalence of overweight and obesity in children and adults during 1980-2013: a systematic analysis for the Global Burden of Disease Study 2013. Lancet 384(9945): 766-781.

11. Chan YY, Jayaprakasan K, Zamora J, Thornton JG, Raine-Fenning N, et al. (2011) The prevalence of congenital uterine anomalies in unselected and high-risk populations: a systematic review. Hum Reprod Update 17(6): 761-771. 
(C) This work is licensed under Creative

BY DOI: 10.19080/JGWH.2017.05.555681

\section{Your next submission with Juniper Publishers will reach you the below assets}

- Quality Editorial service

- Swift Peer Review

- Reprints availability

- E-prints Service

- Manuscript Podcast for convenient understanding

- Global attainment for your research

- Manuscript accessibility in different formats

( Pdf, E-pub, Full Text, Audio)

- Unceasing customer service

Track the below URL for one-step submission https://juniperpublishers.com/online-submission.php 